DRAFT of August 1991. For the final version see Decision Support Systems, December 1992, pp 365-386.

\title{
RECENT APPLICATIONS OF ECONOMIC THEORY IN INFORMATION TECHNOLOGY RESEARCH
}

\author{
J. Yannis Bakos \\ University of California, Irvine \\ Chris F. Kemerer \\ Massachusetts Institute of Technology \\ August 1991 \\ This is a draft version of the article that appeared in \\ Decision Support Systems, December 1992, pp 365-386.
}

Helpful comments on earlier drafts of this article were received from C. Beath, E. Brynjolfsson, V. Gurbaxani, R. Kauffman, C. Kriebel, T. Mukhopadhyay, and J. Whang. 
DRAFT of August 1991. For the final version see Decision Support Systems, December 1992, pp 365-386.

\title{
Recent Applications of Economic Theory In Information Technology Research
}

\begin{abstract}
Academicians and practitioners are becoming increasingly interested in the economics of Information Technology (IT). In part, this interest stems from the increased role that IT now plays in the strategic thinking of most large organizations, and from the significant dollar costs expended by these organizations on IT. Naturally enough, researchers are turning to economics as a reference discipline in their attempt to answer questions concerning both the value added by IT and the true cost of providing IT resources.

This increased interest in the economics of IT is manifested in the application of a number of aspects of economic theory in recent information systems research, leading to results that have appeared in a wide variety of publication outlets. This article reviews this work and provides a systematic categorization as a first step in establishing a common research tradition, and to serve as an introduction for researchers beginning work in this area. Six areas of economic theory are represented: information economics, production economics, economic models of organizational performance, industrial organization, institutional economics (agency theory and transaction cost theory), and macroeconomic studies of IT impact. For each of these areas, recent work is reviewed and suggestions for future research are provided.
\end{abstract}

Keywords: information technology, economics, economic theory, econometrics, information economics, economies of scale, organizational economics, industrial economics, transaction costs, agency theory. 
DRAFT of August 1991. For the final version see Decision Support Systems, December 1992, pp 365-386.

\section{INTRODUCTION}

Recently there has been heightened interest on the part of both academicians and practitioners concerning the economics of Information Technology (IT), where IT is defined as systems for providing context-sensitive data [9]. In part, this interest stems from the increasingly large role that IT plays in the strategic thinking of most large organizations, and in the significant dollar costs now expended by organizations on IT. For example, Kriebel notes that roughly $50 \%$ of new capital investment by major US corporations is in IT [93]. As organizations have improved their ability to manage and deploy information technology, there has been a shift in focus from making the technology work and keeping it working (operations) to understanding, predicting and influencing the micro and macro-level effects of IT on individuals, organizations and the economic system (impact), and especially on how to maximize the return on IT investment. These trends have raised issues concerning the value added by IT and the cost of providing IT resources. IT researchers have turned to economics as a reference discipline, taking advantage of its theoretical and methodological tools in their attempts to answer these questions.

This recent interest in economics has manifested itself in the application of a number of aspects of economic theory in information systems research, leading to results that have appeared in a wide variety of publication outlets. In 1980 Kriebel and Moore reviewed the economics literature in order to suggest a large number of ways in which IT (née MIS) researchers could apply economic theory [95]. The present article updates that list of suggestions by reviewing the work actually done in the IT literature over the last five years (1986-1990). It is hoped that this will help to provide a framework for research in this area, as well as a first step in establishing a common research tradition. Additionally, it should serve as an overview and introduction to the area for new researchers and students. Six areas of economic theory are represented: 1) information economics; 2) production economics; 3 ) economic models of organizational performance; 4) industrial organization, 5) institutional economics (agency theory and transaction cost theory), and 6) macroeconomic studies of productivity. For each of these areas, both a review of recent work and suggestions for future research are provided.

\section{Economic characteristics of IT}

In order to use economic theory to study the impacts and value of information technology, researchers must focus on its most salient characteristics, especially the ones that distinguish IT from other types of capital investments. In this context, there are typically five characteristics of information technology that, when taken together, drive economic studies of this particular technology. 
DRAFT of August 1991. For the final version see Decision Support Systems, December 1992, pp 365-386.

Supply

(a) Information systems typically require large capital investments and they offer substantial economies of scale and scope.

An organization usually must incur large system development and maintenance costs (both fixed and variable); it may then face relatively small incremental costs for each additional transaction until the capacity of the system is approached, resulting in substantial economies of scale. Furthermore, technological and organizational resources and expertise acquired during the development and operation of one system may be transferable to other systems, resulting in economies of scope. The economies of scale and scope found in information systems vary with the particular type of technology (e.g., hardware, software or communications), are larger than those manifested in many other technologies, and their actual structure is the subject of much research [5] [145].

\section{Demand}

(b) The benefits realized by individual users of information technology increase as more users adopt compatible systems.

This property, known in economics as network externalities, can affect the dynamics of the introduction and adoption of information systems, e.g., by creating first mover advantages for technology vendors [81].

(c) Potential adopters of information technology face substantial uncertainty regarding the actual benefits of this technology. Occasionally this uncertainty remains even after an organization has deployed the technology.

This uncertainty can affect the strategic behavior of potential vendors and adopters of information technology, e.g., by inducing them to follow a "wait and see" strategy where they delay introducing or adopting certain systems in the hope that they will learn from the experiences of other organizations [59].

(d) Information systems can impose significant switching costs on their participants.

Information systems may require sizable investments from their participants in hardware, software, employee training and organizational transformations. Such investments may become worthless should the organization decide to switch to a different system or to revert to the pre-technology mode of operation. Competing technology vendors may need to compensate potential system adopters and participants for their switching costs or invent technology that minimizes these costs in order to lure them away from rival systems [138] [88]. 
DRAFT of August 1991. For the final version see Decision Support Systems, December 1992, pp 365-386.

$\underline{\text { Information in organizations and markets }}$

(e) Information Technology can reduce customers' costs of obtaining information about the prices and product offerings of alternative suppliers as well as suppliers' costs of communicating information about their prices and product characteristics to additional customers.

This reduction is likely to affect the monopoly power of the suppliers or the monopsony power of the customers in a vertical market that is moved "on-line" by the introduction of an inter-organizational system, and will also have implications for the efficiency and structure of that market [11].

The above economic characteristics are not exclusive to information technology and can be found in other types of capital investments as well. Information technology stands out, however, because it exhibits all five of the above characteristics. Furthermore, the economic fundamentals of IT are rapidly changing, creating challenges in terms of its economic evaluation and exacerbating the related problems of modeling and measurement. As a result, IT researchers face the task of extending economic theory in the appropriate areas, drawing the proper conclusions, and bringing the relevant results into the information systems field. In the next section, a review of recent work in this area is presented.

\section{INFORMATION TECHNOLOGY APPLICATIONS OF ECONOMICS RESEARCH}

\section{Introduction}

A review of the recent (1986-1990) economics of IT literature identified six specific areas in which economic theory and methodology have been applied to information technology research:

- information economics

- economics of information technology supply

- information technology and organizational performance

- industrial organization

- institutional economics (agency theory and transaction cost theory)

- macroeconomic impacts of information technology

The remainder of this section reviews each of the above areas, following a three-part format. First, a brief introduction to the research theory is presented, with an emphasis on the 
DRAFT of August 1991. For the final version see Decision Support Systems, December 1992, pp 365-386.

assumptions that distinguish this branch from the other five branches. Second, recent research applying this work to IT is reviewed. Third, open research questions and promising areas for future research in relation to IT are presented for each branch. Finally, the last section of this article summarizes the open research questions and suggests some relatively untapped opportunities in other areas of economic research.

\section{A. Information Economics}

\section{$\underline{\text { Background }}$}

Information Economics (IE) can be seen as being at the heart of work done in IT research, as the collection and dissemination of information through information technology are driven by the notion that information has economic value. The study of the role of information by economists is a relatively recent (twentieth century) phenomenon, since classical economic theory postulated 'perfect information' and 'costless information transfer'. The examination of situations that violated these assumptions highlighted the key role of information. Information Economics formally establishes the value of information as its ability to increase the expected utility of a decision-maker.

Information systems research can build on information economics by focusing on the role of information systems in determining the attributes and value of the information presented to this decision-maker. A broad ranging survey and discussion of the literature in this area is found in [95]. Researchers wishing to follow and pursue the current work applying Information Economics to IT should be familiar with classic texts such as Blackwell [30], Marschak and Radner [104] and the collection of papers in McGuire and Radner [105]. Another major work in the area is [122] which showed that, for a certain class of problems, when the marginal cost of information is strictly positive, a small amount of information has a negative marginal net value.

\section{$\underline{\text { Recent Applications }}$}

Ahituv identifies three approaches in assessing the value of an information system. The normative approach attempts to construct theoretical models of the increase in expected utility resulting from the use of an information system. The realistic approach empirically measures performance improvements due to different types of information systems. Finally, the perceived value approach is based on the subjective user assessment of the information system's value [1]. Information Economics primarily subscribes to the normative approach; for example, the papers in McGuire and Radner [105] provide a comprehensive collection of normative results that may be applicable to information systems research. Recent work by Moore and Whinston develops a set of such normative models to form the basis for a formal model of decision support systems [110] [111]. 
DRAFT of August 1991. For the final version see Decision Support Systems, December 1992, pp 365-386.

\begin{abstract}
Ahituv notes, however, that a limitation of Information Economics is that it "does not deal with the mechanism but only with its outcomes" [1, p. 316]. Barua, Kriebel and Mukhopadhyay establish the first links between the formal rigor of information economics and the IT mechanism, specifically the design of the information system [25]. They emphasize the 'payoff-relevancy' [103] of the systems attributes, identify six corresponding attributes of information systems (signal timing, reporting frequency, monitoring time, signal resolution, intrinsic accuracy and intrinsic informativeness) and set forth related propositions regarding alternative system designs.
\end{abstract}

\title{
Ongoing Research Concerns
}

Arguably, information economics has not had much impact within applied IT research to date. One major limitation has been its focus on simple, idealized settings that can be modeled with tractable mathematical models. Real-world information systems involve complex relationships, variables and parameters; even when rigorous models can be formulated they typically cannot be solved analytically. Furthermore, as articulated by Barua et al., very few researchers in this area have gone beyond the theory building (i.e., formal generation of propositions) stage, to the more advanced stage of operationalizing these concepts into empirically-testable hypotheses [25]. Until this is done, information economics may not reach its full potential impact.

One possible solution to this problem may be through related work in the Accounting literature. The economic value of information is of central interest to accountants, particularly in terms of issues such as the impact of various financial and non-financial announcements on securities prices, the value of 'inside information' and so forth. In fact, some accountants view accounting as the 'information system' of the firm. Given the historical ties of real-world information systems departments to the financial arm of the corporation and auditors' reliance on IT to perform their function, many accountants and accounting researchers have considerable interest and expertise in IT-related areas. As a result, work related to the economics of IT is becoming more common in the accounting literature. An example is Banker and Datar's work in examining the information content of performance measurement signals [18]. Researchers interested in this area should therefore, stay abreast of related work in accounting.

\section{B. Economics of Information Technology Supply and Demand}

\section{$\underline{\text { Background }}$}

Given the increasing sums spent on IT, much current practical interest and attention have been focused on the economics of providing IT resources. The area of economics of information technology attempts to look inside the IT black box and study the characteristics 
DRAFT of August 1991. For the final version see Decision Support Systems, December 1992, pp 365-386.

of IT production functions and IT cost functions in terms of historical trends, present capabilities, and future projections. This area warrants a great deal of attention, because advances in the technology have caused significant shifts in the cost of providing IT resources, and therefore have wide effects on what will be feasible uses of the technology. The theory for this area comes directly from classical microeconomics, and is widely disseminated in any number of intermediate level textbooks.

\section{Recent Applications - Hardware Supply}

The earliest work in this stream of research focused on hardware, since it historically was the critical resource. Hardware is seen as a fixed capital type of investment, and the early (and continuing) focus has been on the appropriate scale of this investment. The seminal work in this area was by Grosch, whose basic idea of significant scale economies in 1950s' vintage hardware has been embodied in 'Grosch's Law', which predicts that the cost of providing an additional unit of computing power declines as a square root function of the amount of computing power. Ein-Dor's update of this work argued that this law still held in the 1980s, but only within categories and not across them [56]. Kang et al. extended this analysis, and found that economies of scale did not hold within the category of minicomputers [80]. Mendelson, in a more rigorous examination of the same data, found that a simple constant returns to scale model, with random noise, explained the data equally well, and was more consistent with the managerial trend in the increased use of smaller, decentralized hardware [107]. A convenient summary table of this research, along with recent results, is available in [79].

Of course, while determining the degree of scale economies is of great value in aiding the manager's acquisition decision, there remains the operational problem of pricing the newly acquired shared resource to ensure efficient use. Building upon Mendelson's work [106] in incorporating queueing effects into computer system pricing schemes, Whang develops a theoretical framework in which five alternative mechanisms are studied and compared, and found to be equivalent in terms of their prices and transfer payments [141]. General work expanding the pricing mechanism to accommodate the incentive problems inherent in, for example, requiring users to reveal their true preferences, are investigated in [140] and [108].

\section{$\underline{\text { Recent Applications - Software Supply }}$}

As the relative cost of hardware continues to decline, attention is increasingly focusing on the economics of software. Early software engineering research used research paradigms from computer science and engineering, whereby researchers built prototypes of tools that were expected to reduce the costs of software development and maintenance. The focus is now shifting to the economic evaluation of these tools, to determine whether these tools and techniques improve the labor productivity of software developers and maintainers. 
DRAFT of August 1991. For the final version see Decision Support Systems, December 1992, pp 365-386.

As in the hardware case, the question of returns to scale in software development has attracted interest. The conventional wisdom has been that software development projects exhibited decreasing returns to scale. This view is exemplified in most models of software development, such as COCOMO [31]. However, these models estimate a single parameter to determine the presence of increasing or decreasing returns to scale for an entire data-set of projects. Recent work by Banker and Kemerer used nonparametric estimation techniques to show that in five of the eight data-sets examined, both increasing and decreasing returns to scale were present, with smaller projects tending to exhibit the former, and larger projects the latter [22]. Their work also demonstrates how to estimate the most productive project scale size, and thus has implications for capital investments to support software development.

The problem of selecting the appropriate scale is one aspect of the more general problem of developing cost models for use in software planning estimation. Kemerer tested four such models on a data-set of fifteen completed large-scale software development projects [84]. The four models were found to significantly differ in their accuracy, suggesting the need for continued research in developing such models. Wrigley and Dexter have developed a new model specifically for fourth-generation language environments [146]; their model can be applied relatively early in the development life-cycle, which makes it valuable in practice.

One promising approach to the software productivity and quality problems is a greater dependence on software reuse, whereby proven components are used multiple times. In this manner applications software will be "assembled" rather than "developed", with the expected result being a shorter lifecycle and a more reliable product. A series of papers on the economics of software reuse has come from a project investigating the impact of the SEER Technologies Computer Aided Software Engineering (CASE) tool. In [15], Banker et al. propose variant metrics to support the repository-based approach to software reuse. In [14], Banker and Kauffman find significant productivity gains from use of the CASE tool, attributed to its support of software reuse. Finally, in [16], Banker et al. report on environmental factors that aid or hinder reuse.

A final issue of great practical concern is software maintenance. It is estimated that over half of all IT development expenditures are spent on some kind of software maintenance [32] [49]. Yet, despite this large cost, maintenance has been a relatively neglected area of research $[96,131]$. Gode et al. in a recent paper have proposed a formal, analytic model describing investments in software maintenance [66]. Some recent empirical research has been directed at identifying those factors that affect software maintenance productivity, in order to improve the management of this critical function [19]. An extension of this work addresses the role of underlying system complexity in increasing maintenance costs [20]. In general, however, this remains an under-studied area of research perhaps due to the conceptual difficulties inherent in modeling the phenomena over multiple time periods, and 
DRAFT of August 1991. For the final version see Decision Support Systems, December 1992, pp 365-386.

the difficulties in empirical data collection that are compounded by the longitudinal nature of maintenance.

\section{$\underline{\text { Recent Applications - Demand }}$}

The cost trends in hardware and software naturally have considerable impact on the demand for information systems. Gurbaxani and Mendelson [70, 72] have examined the demand for information services and the resulting impact on information systems spending.

Gurbaxani and Mendelson [70] developed a microeconomic framework for the evolution of information systems budgets over time, and in particular, the allocation of these budgets between hardware and software, including software personnel. Their model draws from the economic theory of production to analyze the provision of information services. It regards software and hardware as inputs to the process of producing information services, and identifies the complementarity and substitution between them as major determinants of efficient budget allocation. They show that when the production of information services is modeled by the Cobb-Douglas production function, the budget shares allocated to hardware and software remain constant over time, while the overall budget grows over time. The predictions of this model are seen to be consistent with data on information systems spending for the years' 1976-1984 in the United States. The finding of constant software and hardware budget shares is noteworthy given the considerable differences in their respective cost trends.

Gurbaxani and Mendelson [72] examine the pattern of overall information systems spending growth in the United States for the years' 1960-1987. They suggest that in order to develop a comprehensive model of the demand for information services, it is necessary to integrate the effects of the diffusion of innovation with the price effects. Traditional studies of the demand for computing have focused only on the impacts of innovation diffusion, while ignoring the effects of price on the growth process. Their integrative model results in a price-adjusted Scurve growth pattern of information systems spending. In this model, the early pattern followed an S-curve as diffusion effects were dominant then, but more recent growth has converged to an exponential growth pattern as price effects began to dominate learning effects. Gurbaxani and Mendelson demonstrate the consistency of the predictions of their model with the data on information systems spending growth.

\section{Ongoing Research Concerns}

The recent research, as described above, has focused on a number of critical individual pieces of the cost of providing IT resources. Taken as a whole, this research has, as its theme, the development of a greater understanding of how information systems providers can make the transition from a labor-intensive craft industry, to an increasingly capital-intensive production environment. As IT expenditures become increasingly large, practical interest in 
DRAFT of August 1991. For the final version see Decision Support Systems, December 1992, pp 365-386.

reducing the cost of delivering IT-services continues to grow. Therefore, a promising approach for research in the economics of IT supply may be to study similar transitions in other industries that should provide clues as to what effects might be expected in information systems. John Kenneth Galbraith has outlined six "technology effects hypotheses" that reflect how industries make the transition to production environments [64]. They are: a) increased timespan from inception to implementation, b) increased capitalization, c) greater inflexibility of investment, d) greater specialization of labor, e) larger organizations, and f) increased planning.

Some evidence for these trends has already appeared in software production [85], and more research could usefully be devoted to testing these hypotheses in order to provide insights into how better to manage the process. For example, the first and fifth effects correspond roughly to increased scale. Building on the current work in measuring most productive scale size, a next research step is to determine why some organizations have a larger most productive scale size [22]. Regarding Galbraith's second hypothesis, many questions have been raised about the productivity impact of the increased capitalization of software development in the form of CASE tools. Economic theory can aid this research by providing the concept of the marginal rate of technical substitution (MRTS) of CASE tools for software engineering labor. Empirical research could usefully be directed at determining an optimal capital/labor mix, given a set of factor prices.

From studies of other industries making the transition to production environments, one barrier to adopting a capital-intensive development approach is the presence of up-front learning costs, a factor that sometimes discourages the more rapid adoption of innovations in practice. A lack of knowledge of the likely learning costs may serve to discourage early adopters, or may cause adopters to shift too rapidly from one approach to another, before the benefits of the initial approach can be realized. As applied to information systems development, the tendency in software development is to speak of learning costs, rather than the learning curve. The problem with this approach is that, by focusing on the early portion of the learning curve, it fails to take advantage of the benefits of experience, or the later portion of the learning curve. Firms with data on their learning rates will be able to predict future costs with greater accuracy since learning effects can be factored in. Benefits of this approach for software developers could include: a) improved ability to evaluate the productivity impacts of new tools with significant learning effects, such as CASE, b) improved accuracy of cost estimates, c) better understanding of the appropriate timing for the adoption of new technologies or the retention of proven approaches, and, eventually, d) a reduction in costs stemming from a greater understanding of how learning occurs, what factors affect it, and how learning time can be shortened. 
DRAFT of August 1991. For the final version see Decision Support Systems, December 1992, pp 365-386.

\section{Information Technology and Organizational Performance}

While the economy can be seen as a complex network of firms competing in different markets, individual firms are often viewed as organized systems of numerous owners, managers and employees who may cooperate toward the achievement of common organizational goals. Adopting this perspective, Bakos and Treacy suggested that a firm can use information technology to obtain competitive advantage either 1) through superior efficiency, or 2) through market power [12]. In this section, economic and decision-theoretic models of organizational efficiency are discussed, as well as attempts to empirically document the organizational benefits resulting from investments in information technology. Section D, Industrial Organization, focuses on the potential use of the technology to acquire and sustain market power.

\section{Background}

In his widely-cited work, Galbraith studied the information needs of different types of organizations and the link between organizational information processing and organizational performance, speculating that information technology, by affecting the former, would have a significant impact on the latter [62] [63]. Following that tradition, the focus of study in this area has been to theoretically model and empirically document the improvements in organizational efficiency resulting from cost reductions, performance increases and organizational restructuring (such as adopting new organizational forms to perform a certain task) made possible by information technology. The problem domain of this area, improving the performance of organized cooperative systems, is addressed by several disciplines; as a result, research in organizational efficiency has been multi-disciplinary, drawing on areas like control theory, operations research and computer science, as well as economics. These disciplines have provided both analytical modeling as a tool for theoretical analysis, as well as measurement instruments for empirical research.

Another body of work, often referred to as the "IT Value" stream of research, focuses on estimating and measuring the organizational benefits resulting from investments in information technology. Financial analysis techniques such as DCF (discounted cash flows) and NPV (net present value analysis) are the standard estimation tool, although they often suffer from severe limitations [55]. One early piece of research in this area was the work of Cron and Sobol who used ratio analysis to relate information technology investment inputs to business value outputs [51]. A second research effort around the same time was Stabell and Forsund's use of frontier analysis to estimate firm efficiency, which was then related to measures of information systems use [135]. Both of these articles report fairly inconclusive results. Crowston and Treacy surveyed several theoretical and empirical studies of organizational performance published in the period 1979-1985 and concluded that a major impediment to the quality of empirical research in this area is the lack of underlying 
DRAFT of August 1991. For the final version see Decision Support Systems, December 1992, pp 365-386.

theoretical disciplines that would have provided well-developed dependent variables [52]. Bakos recommended that empirical work should attempt to measure intermediate (process) as well as firm and industry level variables to compensate for the large number of confounding factors and the numerous sources of extraneous variance [10]. He also proposed a number of candidate dependent variables derived from organization theory and economics.

\section{$\underline{\text { Recent Applications }}$}

Malone considers organizational performance in terms of three dimensions: production, coordination and flexibility. He uses organizational flexibility as a proxy for the performance of alternative organizational forms in a changing environment, modeling it in terms of vulnerability (the cost of expected failures) and adaptability (the cost of necessary adjustments). This leads to predictions on the implications of advanced information technology for organizational performance [98] [102]. Bakos modeled the impact of the bandwidth and response time of communication links in certain types of organizational couplings, such as a buffered supplier-customer link; he found that improved performance of these "information links" results in increased efficiency due to reduced inventories and better monitoring [11].

Studying the ability of information technology to affect organizational efficiency, Chismar and Kriebel showed how data envelopment analysis (DEA) can be used as a diagnostic tool to identify efficient frontiers for organizational applications of information technology and provided a numerical example [40]. Paul Strassman has proposed a measure called "Returnon-Management" which he contrasts with previous approaches in a useful overview paper [136]. Kauffman and Parker and Benson introduced the "business value linkage" framework, which formalizes the idea of measuring the intermediate process variables in the transformation of inputs, including IT, to economic outputs, based on economic models of the organizational value-added chain [82] [117]. Kauffman and Kriebel discuss assessing the impact of IT on cost reduction and revenue enhancement, using techniques such as DEA and models of intermediate production variables [94]. Banker and Kauffman modeled intermediate production in retail banking and thus developed and measured an economic model of the impact of ATM investment on branch market share [13]. In a more recent paper, they use the same data set to provide a detailed illustration of their "business value linkage" modeling approach [21]. Barua et al. expand on the "business value linkage" idea, proposing a "value chain" (multi-level) model of intermediate production; they proceed to develop a two-level model, which they test with secondary data from the manufacturing sector [23]. They claim that this approach can lead to a better understanding of the process by which IT investments generate value, as well as identify areas that require managerial attention. 
DRAFT of August 1991. For the final version see Decision Support Systems, December 1992, pp 365-386.

In an effort to establish a conclusive link between information technology expenditures and increased organizational efficiency and profitability, Harris and Katz analyzed data on insurance companies derived from the Life Office Management Association (LOMA) database, which captures data on premium income, operating expenses and technological sophistication. They found that the most profitable firms were most likely to make large investments in IT both in absolute terms [74] and as ratios to premium income [75]. Venkatraman and Zaheer carried out a controlled quasi-experimental study of the role of dedicated electronic integration between an insurance carrier and its independent agents. Their preliminary results indicate an increase in the number of policies underwritten by the integrated agents, which failed, however, to improve their financial performance [137]. Kauffman and Weill reviewed 13 empirical studies of the business value of IT, identifying the strengths and weaknesses of each approach [83]. They conclude with a number of recommendations, including the need for additional theory building on IT impact, more utilization of longitudinal data, and purposeful survey research motivated by theoretical models.

\section{$\underline{\text { Ongoing Research Concerns }}$}

An emerging research area is the study of coordination in complex systems, including organizations, markets and economic systems [99, 101]. The National Science Foundation has recently launched two Research Initiatives on Coordination Theory and Technology, which have fueled research on the potential of information technology to affect coordination $[112,113]$. This research is interdisciplinary in nature, drawing on areas like computer science, operations research, control and decision theory, organization theory and sociology, as well as economics. It aspires to provide a formal theory of coordination, identifying and modeling the role of the salient variables in complex coordinated systems, and establishing appropriate hypotheses related to the performance of these systems.

One related area of study is the potential of information technology to allow optimization over larger domains. For example, organizations may be able to use IT to perform global rather than local optimization and to achieve tighter coupling of organizational units, especially across organizational frontiers (e.g., with one's customers and suppliers). The importance of this area is emphasized by the increasing role of organizational partnerships and strategic alliances, which aspire to promote tighter coupling between firms and the global optimization of their operations. Economics and decision theory can be used to model, and econometric techniques may be able to measure the impact of IT in this area. Theoretical and empirical work has been proposed along these lines, for example the use of economic theory in conjunction with sociological approaches to model and measure the impact of JIT and MRP II systems on organizational processes and performance [92]. 
DRAFT of August 1991. For the final version see Decision Support Systems, December 1992, pp 365-386.

In the area of evaluating IT investment decisions, option pricing theory has been often suggested as an appropriate tool [115] [109] [86]. Dos Santos discusses and illustrates how option valuation models can capture the potential of information technology to support (and thus enable) strategic alternatives in the future [55]. Much remains to be done regarding the measurement of IT impacts on organizational performance as well. Rigorous empirical work in this area may finally reveal whether and to what extent information technology lowers production costs by providing an efficient input factor.

The major obstacle in empirically assessing the impact of IT has been the multitude of confounding factors for firm-level measures of performance. This requires either controlled studies (such as quasi-experiments), which are difficult to carry out because few settings can be adequately controlled without an excessive expenditure of resources, or more sophisticated measurement models, more powerful analysis techniques, and improved data sets. It was seen how the "IT Value" line of research has progressed into modeling and measuring intermediate process variables, resulting in models that better represent the process of production and the contribution of IT. A second trend in evidence is the move towards the use of large and rich longitudinal data sets, combined with sophisticated analysis techniques, and away from single-period cross-sectional data, as suggested by Kauffman and Weill [83]. Alpar and Kim, for example, compare analyzing a set of data employing certain "key" input/output ratios (such as the ratio of IT investment to operating profits) with an econometric analysis based on a sophisticated model of the firm as a multi-factor production function [2]. Although it is uncertain whether the quality of the data set used to illustrate the model can justify the use of the sophisticated model employed, this approach clearly represents a move in the right direction.

\section{Industrial Organization}

\section{$\underline{\text { Background }}$}

Industrial Organization (or industrial economics) refers to the broad field within microeconomics that studies business behavior and its implications for market structure and market processes. Industrial organization replaces the traditional model of "perfectly" competitive markets with explicit models of imperfect competition, with a major focus on the implications for strategic behavior. Information Technology research in this area draws on theoretical and empirical tools to study the strategic impact of information technology, i.e., its ability to be used as a tool for strategic manipulation in order to acquire and sustain market power.

The economic literature on firm performance and behavior has grown explosively in the last decade. Schmalensee and Willig provide an excellent overview [130]. Major streams of research in industrial economics with interest for information systems research include: 
DRAFT of August 1991. For the final version see Decision Support Systems, December 1992, pp 365-386.

- The theory of structural barriers to entry or exit and mobility, and the implications for the advantages of incumbency and the strategies of new entrants.

- The consequences of imperfectly informed buyers for market structure and conduct, and the implications for investments (such as advertising or information systems) that affect buyers' information endowments.

- Investments in R\&D and the timing and dissemination of innovations (such as new information technology).

- Economic characteristics of standards and the processes underlying their introduction and adoption leading to their ultimate success or failure.

- Switching costs imposed by technology vendors on technology users, and their implications for strategic conduct and economic efficiency.

These areas have direct or indirect implications for IT research. As discussed below, substantial work already exists that draws on these areas, yet there is still a large number of untapped potential applications to information systems problems. As long as the work is theoretical, information systems research in these areas will typically require a good economic background. As the theoretical work leads to testable propositions and as the appropriate empirical tools are developed [129], this area may appeal to a broader group of IT researchers.

\section{$\underline{\text { Recent Applications }}$}

Porter has popularized the basic concepts underlying several of the above streams of Industrial Organization research, such as structural barriers to entry and exit, product differentiation and vertical contracting relations with customers and suppliers. [120]. These concepts subsequently were applied to earlier IT research (e.g., [121], [126], [12] etc). Recent work in this area has started to take advantage of the rich theory that IO economists have developed in the last decade.

Analytic work:

An area that has been a direct beneficiary of recent IO research is the study of IT standards, which has drawn extensively on economic models for network externalities and switching costs. Several papers on the adoption, impact and evolution of standards in IT industries and markets were presented at the Conference on Compatibility Standards and Information Technology: Business Strategy and Public Policy Issues. ${ }^{1}$ David discussed the dynamics of rival IT standards with a focus on policy issues [54]. Besen and Saloner analyzed the process

\footnotetext{
${ }^{1}$ Center for Economic Policy Research, Stanford University, Palo Alto, California, February 24, 1989. Proceedings available from Center for Economic Policy Research.
} 
DRAFT of August 1991. For the final version see Decision Support Systems, December 1992, pp 365-386.

by which standards are produced in the telecommunications industry, contrasting voluntary standards that are established cooperatively and de facto standards that are established by the market [29]. Saloner (1989) applied switching cost theory to the study of open systems, finding that governments or user groups can precipitate the emergence of standardized computer interfaces [127]. Salop studied joint pricing in shared ATM networks, and concluded that competitive pricing is generally efficient given the difficulties of regulatory price setting [128]. Greenstein modeled a setting where a technology vendor controls system specifications and examined the strategic constraints imposed on that vendor and its competitors by considerations of backward compatibility [67]. The approach taken by economics researchers in this area provides an example for how IT researchers may approach theoretical issues dealing with the linkage between IT and industrial organization.

Exploring the implications of information technology on industrial markets, Bakos studied the implications of employing information technology to reduce buyers' search costs in differentiated product markets. He found that such reductions would result in efficiency gains both from the avoided search costs and from improved allocational efficiency resulting from the better choices of the better informed buyers [11]. Chismar and Meier modeled a setting with two competing proprietary inter-organizational systems and studied the resulting partitions in system adoption; they identified switching costs and network externalities as critical determinants of the outcome [39]. Nault studied formal pricing models for interorganizational information systems offered to consumers, concluding that under certain conditions multi-part tariffs are optimal, although the pricing problems for the constituents of these tariffs are interdependent [114]. Whang extended Arrow's work on information acquisition and vertical integration [6] to study under what circumstances a customer and a supplier would be willing to share information through an inter-organizational system [142]. He also identified conditions under which either full information sharing occurs in equilibrium, or none at all. Finally, Barua et al. and Davamanirajan et al. developed models for the impact of information technology investments on quality-based competition in a duopoly setting and in the presence of customer switching costs [24] [53]. They show that these switching costs create inefficiences, similar to those reported in $[90$ and Klemperer, 1987 \#128].

\section{Empirical and other work:}

Recognizing the need for empirical work in this area, Bakos proposes a number of dependent variables characterizing industrial structure and industrial conduct that can serve as indicators of the strategic impact of IT; he identifies the importance of developing appropriate measurement instruments that will enable data collection [11]. Along this line of inquiry, Hartman and Teece estimated a model of firm performance in the minicomputer industry using 1976-83 data; they found that product price-performance, network externalities of installed base and manufacturer reputation effects are all significant in determining vendors' 
DRAFT of August 1991. For the final version see Decision Support Systems, December 1992, pp 365-386.

market share [76]. Banker and Kauffman modeled and measured the contribution of ATMs to branch market share [13]. Their findings failed to establish a link between the presence of ATMs and branch market share, but identified a willingness by consumers to pay for the network externalities they enjoyed when their bank participated in a larger ATM network.

Investigating the underpinnings of competitive advantage, Clemons and his colleagues have conducted a number of studies in this area. Clemons and Kimbrough [44] noted that major shocks and discontinuities in the economic environment create strategic opportunities. In a related paper, Clemons and Row [45] argued that information systems that exploit unique characteristics of firms are more likely to create defensible and sustainable competitive advantage compared to systems lacking such an edge. Clemons and Adams [43] offered a descriptive account of the market efficiency implications of the "Big Bang" deregulation of the London Stock Exchange in October 1986, and the subsequent adoption of electronic securities trading. Clemons and Row [46] argued that information technology creates competitive advantage by altering the economics of resource utilization throughout the economy; "electronic hierarchies," for example, can create economies of scale and scope beyond those achievable by traditional forms of economic organization. Finally Clemons [42] presents a series of case studies in the context of which he draws seven lessons on the appropriateness of techniques such as decision trees, risk analysis and net present value calculations in evaluating strategic information systems, and discusses the role of the nonquantifiable considerations that enter these decisions.

Finally, work at the intersection of financial economics and the information systems field has investigated the role of information technology in financial markets. In an important early article in this area, Garbade and Silber showed how improvements in communication technology, such as the introduction of the telephone, resulted in reduced security pricing discrepancies across financial markets [65]. While reviewing the extensive literature on market microstructure is beyond the scope of this article, The events surrounding the October 19, 1987, stock market crash have renewed interest in the impact of computerized trading systems. Cohen and Schwartz, for example, discuss a proposal for an automated call market [48]. Peakeet al. propose a fully electronic trading system that would address the shortcomings of existing systems that contributed to the 1987 crash, as well as improve market efficiency [118]. Amihud and Mendelson report results on liquidity, volatility and exchange automation, and offer their own proposals for the design of electronic trading systems [3].

\section{$\underline{\text { Ongoing Research Concerns }}$}

Future research should build on industrial organization theory studying investments in ways of interest to information technology researchers. Economic theory on new technology should be leveraged as well, and information technology researchers face the task of drawing 
DRAFT of August 1991. For the final version see Decision Support Systems, December 1992, pp 365-386.

the appropriate conclusions and bringing the relevant results into the IT field. Four areas in which theoretical developments in the last decade are likely to have substantial IT-related applications are suggested as sources for IT researchers to draw upon.

Strategic investment: The large investments in sunk (entry) and fixed costs that characterize information technology can have strategic impact. These costs can raise entry barriers [133] and offer advantage to early movers [61]. Incumbent firms may over-invest early in the game and keep investing just enough to discourage future entry [28]. The underlying economies of scale [50] and the uncertainty about the costs and benefits of the technology and the actual demand for information services [7] determine the contestability of the market and the corresponding equilibrium outcomes; if more firms enter than the market can support, the result may be a war of attrition. An important characteristic of information technology in this setting is the potential for second mover advantage, since duplicating certain types of information systems may be substantially cheaper than their initial development.

Switching costs: It is often argued that firms deploying information systems may face substantial technological and organizational costs if they decide to switch to an alternative technology; such switching costs are a central element of the IT strategic environment. The study of the strategic implications of switching costs has emerged as an active field in industrial economics with the work of von Weizsaker [138], Farrell [58], Farrell and Shapiro [60] and Klemperer [87, 88, 89, 90]. Analytic models of switching costs tend to predict aggressive behavior of early movers, who try to build a locked-in customer base that can be subsequently exploited. The actual results depend on the specific assumptions about technological evolution, arrival of new potential users, and economic benefits accruing to users. Identifying the precise characteristics of the switching costs imposed by different types of information systems on their participants and integrating these results with the theory of switching costs is an interesting path for future research in this area.

Learning curve, technological progress, and diffusion of know-how: These factors are clearly important in determining the sustainability of any competitive advantage developed through Information Technology. If there is a learning curve in operating costs, for example, early movers that can gain large market shares will enjoy an advantage from riding that curve comparable to their network externalities [134]. On the other hand, if the technology evolves fast, early movers may be stranded with obsolete technology and left serving a declining market segment. If the learning curve effects are diffusible, later movers may be able to duplicate the functionality of early systems at a smaller cost [4]. This may create a "late mover" advantage. Answering these questions for different types of information systems is an open area of research.

Timing of innovation and planning for obsolescence: Economic theory in these areas may have interesting implications for information technology, such as whether vendors should 
DRAFT of August 1991. For the final version see Decision Support Systems, December 1992, pp 365-386.

build planned obsolescence into their systems, how uncertainty about technological developments affects IT users, and how the timing of the introduction of new generations of the technology affects the users' decisions on technology planning and acquisition [123] [38]. To this date IT researchers have not drawn on this area of economic theory.

\section{E. Institutional Economics}

\section{$\underline{\text { Background }}$}

Institutional Economics (sometimes referred to as Organizational Economics) is the label applied here to the branch of economics that studies the comparative costs of alternative economic institutions, referred to as governance structures in this literature. Institutional Economics focuses on the implications of the fact that firms within the economy as well as individuals within a firm are self-interested economic agents with divergent objectives. Broadly speaking, it consists of transaction cost theory, clan control and agency theory, although only the first and the third of these have received sufficient attention in the IT literature to merit review here.*

Both transaction cost theory and agency theory focus on the nature of the contracting relationship between multiple parties. They explicitly acknowledge that bounded rationality and self- interest expressed as goal incongruencies on the part of these parties may make some of the standard 'rational man' assumptions inappropriate for modeling these contracting relationships. Both of these theories explicitly acknowledge and pay particular attention to the issue of uncertainty in the contracting relationship, and in the role of information to alleviate the problems caused by this uncertainty.

Despite these similarities, there are a number of differences. Eisenhardt provides a succinct review of these differences, beginning with their origins in different economics problem areas (i.e., transaction cost theory focusing on the boundary between markets and firms, and agency theory focusing on the nature of firms [132]). She also notes a number of distinctive variables, particularly agency theory's inclusion of the notions of risk aversion (typically on the part of the agent in a principal-agent relationship) and information as a commodity (the

\footnotetext{
Institutional Economics is sometimes considered a part of Industrial Economics, e.g., there is a chapter on agency theory (Chapter 2 by B. R. Holmström and J. Tirole) and a chapter on transaction cost theory (Chapter 3 by O. E. Williamson) in the Handbook of Industrial Organization [130]. These two areas of research have acquired distinct identities, however, based on their focus on the form of economic contracting structures (transaction cost theory) and the roles of the participants (principals and agents) in the contract (agency theory). Therefore, they are considered separately from Industrial Organization here. This distinction is especially valid for IT researchers, as the settings and questions addressed by transaction cost theory and agency theory are quite distinct from those addressed by other areas of Industrial Organization that focus on strategic behavior in an industrial setting.
} 
DRAFT of August 1991. For the final version see Decision Support Systems, December 1992, pp 365-386.

notion that the parties to the contract can purchase information through information systems to reduce information asymmetries, for example) which are not discussed to any degree in the typical transaction cost literature [57]. Furthermore, while transaction cost theory tends to focus on an economic exchange (transaction) as the unit of analysis, agency theory tends to focus on the goal divergence of the parties involved.

\section{Transaction Cost Theory}

\section{$\underline{\text { Background }}$}

The essential distinction in transaction cost theory is between two governance structures, markets and hierarchies. Markets are relatively decentralized control structures where supply and demand are regulated by way of the price mechanism [47] [144]. Hierarchies are relatively centralized control structures whereby a central authority is deemed to possess sufficient information to perform all the coordination of supply and demand requirements. Transaction cost theory described conditions under which each of these two pure forms of governance is likely to emerge. For example, the theory contains the notion of asset specificity, the degree to which an asset can be easily redeployed by other agents, to describe properties of the factors of production that may make, in this case, hierarchies more likely.

\section{$\underline{\text { Recent Applications }}$}

Two areas of IT have been proposed as profitable applications of transaction cost theory. At the more micro level, the systems development process is suggested as amenable to analysis through the transaction cost theory lens. An early proponent of this view was Ciborra, who argued that existing models of the systems development process were excessively rational in their expectations about how the end users viewed the systems being developed for them [41]. In particular, he notes that, at best, the parties to systems development projects have 'mixed interests,' and that systems development methodologies should explicitly recognize this. Beath carried this point of view further by studying fourteen actual projects in terms of their transaction governance structures [26]. In an in-depth examination of four case studies, she found clear relationships between project performance and the degree to which the governance structures 'fit' the problem domain.

At a macroscopic level, transaction cost theory has been employed to explain and predict changes in industry structure resulting from IT. Malone, Yates and Benjamin highlight the role of IT in predicting and interpreting a number of probable changes in the structure of markets and in so doing coined the terms "electronic markets" and "electronic hierarchies"[100]. In particular, they argue that IT will decrease coordination costs and will lead to more goods and services being provided through market, rather than hierarchical structures. Clemons and Row essentially agree with this view, although they supplement 
DRAFT of August 1991. For the final version see Decision Support Systems, December 1992, pp 365-386.

arguments based on transaction cost theory with reasoning from a resource view of the firm [119], and conclude that other competitive outcomes are possible as well [46]. Gurbaxani and Whang proposed a descriptive model of a firm drawing on both transaction cost theory and agency theory to study the impact of information technology on two aspects of firms, firm size and the allocation of decision-making authority among various actors [73].

Another emerging stream of research attempts to document the impact of information technology on industrial structure variables, such as vertical integration and firm size. Brynjolfsson, Malone and Gurbaxani analyzed longitudinal data on IT investments in a number of U.S. industries and they found some evidence that increased information technology investments lead to a move towards market-oriented governance structures, possibly because of reduced transaction costs [36]. Brynjolfsson et al. analyzed similar data on IT investments to show a relationship between increased levels of information technology usage within an industrial sector and smaller firm size as measured by the number of employees per firm [37]. They found that the decline in firm size was greatest after a lag of two years.

\section{$\underline{\text { Ongoing Research Concerns }}$}

The work applying transaction cost theory to date has mostly focused on hypothesis creation. At both the microscopic (systems development) and macroscopic (organization of economic activity through markets or hierarchies) levels, empirical work is needed to test and subsequently refine these hypotheses. In the micro case this will most likely take the form of survey-type instruments that can be used to judge the degree in which differing governance structures are employed. In the macro case, measures of the proportions of transactions consummated in market versus hierarchical settings are desirable, although these may be difficult to collect and verify due to the sometimes sensitive nature of intra-firm data. The development of surrogate measures to 'stand-in' for the pure metrics might be an appropriate first step.

Another interesting application of transaction cost theory may be in the current debate about the relative merits of outsourcing information systems services. Transaction cost theory's clear focus on the distinction between internal and market-based solutions would seem to provide a solid theoretical base of support for launching investigations into this area of current practical concern. 
DRAFT of August 1991. For the final version see Decision Support Systems, December 1992, pp 365-386.

\section{Agency Theory}

\section{$\underline{\text { Background }}$}

Agency theory views firms as a nexus of agency relationships among individual economic agents. Such relationships occur whenever one party (the principal) employs another party (the agent) for the performance of certain actions that affect the principal's economic utility. More formally, Jensen and Meckling define an agency relationship as “... a contract under which one or more persons (the principal(s)) engage another person (the agent) to perform some service on their behalf which involves delegating some decision making authority to the agent" [78]. In an organizational context, a firm enters into agency relationships with its employees in part to exploit economies of specialization. Yet, these employees often act in a manner that is inconsistent with maximizing the welfare of the firm. Agency theory argues that this behavior is typical of agency relationships because: (a) the goals and objectives of the agent are often inconsistent with those of the principal ("goal incongruence"), and (b) the principal cannot perfectly and costlessly monitor the actions and the information of the agent (resulting in "information asymmetries").

Firms would benefit if employees could be trusted to act in a manner maximizing organizational welfare. Ideally, this could be achieved if all information was costlessly shared, remedying the agents' advantage in being better informed about their tasks than their principals, or if the goals of the principals and the agents were made compatible through appropriate incentives. The economic loss that occurs due to the absence of such ideal conditions is called an agency cost. Agency costs can be differentiated into monitoring costs incurred by the principal to observe the agent, bonding costs incurred by the agent to make his or her services more attractive, and residual loss, which is the opportunity cost of not having the principal execute the task, presumably resulting in a less efficient outcome [78]. In view of the existence of agency costs, a rational, value-maximizing principal will seek to minimize agency costs through the use of appropriate control mechanisms. The primary control mechanisms employed by most organizations are the performance measurement and evaluation system, the incentive (reward and punishment) system, and the assignment of decision rights among organizational participants [77].

\section{$\underline{\text { Recent Applications }}$}

Kriebel and Moore, in their 1980 seminal article describing potential applications of economic theory to information systems, suggested that agency theory "fits nicely" with a number of management information systems problems [95]. Since that time, however, there have been relatively few such applications, as pointed out by Gurbaxani and Kemerer [68]. One area of current interest is in applying agency theory to the centralization/ decentralization debate concerning end user computing. Beath and Straub argue that agency 
DRAFT of August 1991. For the final version see Decision Support Systems, December 1992, pp 365-386.

theory provides an explanation for how organizations choose to deliver their computing services [27]. Gurbaxani and Kemerer show how agency theory applies to the cost vs. profit center, and transfer pricing questions [68] and to the questions of why end user computing is chosen, even when traditional economic arguments might argue for continued centralized development and operation [69]. Klepper has shown how agency theory provides an explanation for the apparent paradoxes surrounding the perceptions and realities of information centers [91].

\section{Ongoing Research Concerns}

Some current theoretical work by Whang addresses the contracting problem involved in software development [143]. Banker and Kemerer develop a principal-agent model to examine the role played by metrics in the performance evaluation of software developers [17].

Some recent research by Brynjolfsson using agency theory treats IT as an independent variable and models its impact on organizational structure [34]. He analyzes changes in decision authority, compensation structure, and firm boundaries that may be associated with IT and tests some of the predictions empirically.

In terms of future work, a critical issue with the further application of agency theory is how to operationalize the various agency theory constructs, such as "information asymmetries" and "goal incongruence". Since a critical test of the usefulness of any theory is its ability to explain and predict empirical events, the development of operationalizations will be necessary to advance the current state of the research in this area.

\section{F. Macroeconomic Impacts of Information Technology}

\section{$\underline{\text { Background }}$}

Macroeconomics is a broad sub-area of economics dealing with economic variables at the economy-wide level of aggregation. There have been two streams of IT-related work falling in this area, both using econometric data to study the impact of information technology on productivity and on industrial structure. A cogent introduction and review of this area is provided in Brynjolfsson and Bimber's working paper [35].

\section{$\underline{\text { Recent Applications }}$}

A number of recent studies have analyzed national-level data (typically sector-specific) in an attempt to quantify the productivity impacts of information technology investments. Bureau of Economic Analysis data suggest that the share of capital stock accounted by information technology has increased three-fold between 1980 and 1985 (from 2 to 6 percent) and 
DRAFT of August 1991. For the final version see Decision Support Systems, December 1992, pp 365-386.

preliminary data show that it may have further doubled or tripled between 1985 and 1990 [37]. Allowing for the overall growth in capital investment, the increase in computing price/performance, and expensed investments in information technology (often the case with personal computer software, for example), an order of magnitude increase in hedonically adjusted deployed computing power may have taken place in the 1980 s.

These studies have fueled a controversial debate, primarily because they have failed to document substantial productivity improvements attributable to information technology investments. Loveman found the marginal productivity of information technology to be less than that for other factors of production, suggesting that the (American and European) firms studied over-invested in IT [97]. Baily and Gordon found no evidence that IT investments had a positive impact on white collar productivity [8]. Roach [125] found that white collar workers in information intensive industries were not able to increase their productivity regardless of the amounts of IT invested. Osterman, in a labor-economic study of the impact of information technology on employment found that IT introduction had an initial displacement effect on clerical and managerial labor, which was temporary in nature, followed by a rebound effect to the original employment levels two years later [116]. Bresnahan used the area under the "intermediate input derived demand curve" for IT as a measure for social welfare in the financial services sector [33] to identify significant efficiencies subject to the caveat that no direct benefit measures were employed; the results hinge on the assumption that firms will employ socially optimal amounts of information technology as an intermediate factor of production.

\section{$\underline{\text { Ongoing Research Concerns }}$}

More research is necessary to conclusively document the impact (or lack thereof) of information technology on productivity or on the emerging organizational and economic trends (such as the predominance of smaller firms, the move to a service-based economy, the appearance of new organizational forms such as network organizations and adhocracies, etc.). Other economy-wide issues may arise as well, such as the relationship between information technology investment and comparative economic performance at the national level. Presently the national significance of IT investment has been the subject of speculation, rather than rigorous research. The major difficulties in this type of econometric research lie in separating the impact of IT from the numerous confounding variables and in the proper measurement of economic output (for example, very complex hedonic indices are required to measure the convenience, flexibility and increased quality often afforded by information technology). 
DRAFT of August 1991. For the final version see Decision Support Systems, December 1992, pp 365-386.

\section{CONCLUDING REMARKS}

The broad survey of recent work offered in this article suggests that the economics of IT have received substantial attention from IT researchers over the last five years. This interest is also apparent from such research infrastructure as the new Workshop on Information Systems and Economics (WISE), held for the first time in December 1989 in Cambridge, Massachusetts, in December 1990 in Copenhagen, Denmark, and currently scheduled through December 1992 in New York and Dallas, Texas. As research in information systems and economics grows in interest and acceptance, it can be expected that a cumulative tradition will begin to emerge, which will have the salutary effect of improving the quality of the work. This type of effect is well-illustrated by the example of the hardware economies of scale steam of research, supra. By carefully building on previous work, and having access to common data-sets, a great amount of progress has been made in this area. Many of the other areas reviewed in this article can only show early, exploratory work. It can be expected, however, that as these areas start building a cumulative tradition and start providing useful insights into the economics of IT, they will experience continued growth.

As has been outlined in the discussion of individual areas, there is a long list of future research remaining to be done within each area. One clear theme across the six areas is the need for more attention to be paid to the problem of measurement. For example, theoretical work in information economics and in institutional economics will clearly benefit from the development of measurement instruments that can confirm the validity and estimate the values of their theoretical constructs in real settings, and to determine to degree of explanatory power of these approaches as well. Furthermore, it can be argued that researchers' limited ability to show positive net benefits of information technology applications can be attributed to the shortcomings of current measurements. Essentially, given the large amounts of money invested in IT, net benefit accrual must be positive, assuming rationality on the part of managers making the investments. It may therefore be hypothesized that the benefits are present, but are simply not being measured correctly with the current approaches. Better measures will need to be put into place in order to determine whether this is indeed the case, or whether alternative explanations (such as the hypothesis that the majority of benefits have accrued to workers, increasing their quality of work life) are more likely.

While clearly much work remains within the six areas outlined in this article, there are also opportunities in areas of economic theory, (some identified by Kriebel and Moore [95]), that are still relatively untapped by IT researchers. Perhaps the most glaring omission is that of team theory [104], although some very recent work has outlined how contract theory in general might be usefully applied to a number of IT research questions [124]. Galbraith's information processing view of organizations is another area that might merit further attempts at modeling. 
DRAFT of August 1991. For the final version see Decision Support Systems, December 1992, pp 365-386.

This raises the question, however, of how to select the area to draw upon for IT research from what may appear as a smorgasbord of tempting economic theory? Leaving aside possible competency-related concerns, it is proposed that IT researchers should seek to identify those areas of economic theory that are most directly related to the five economic characteristics of IT listed at the beginning of this article, namely: scale, externalities, uncertainty, switching costs and information costs. It is these characteristics that drive much of the reasoning about IT, and therefore are the aspects of the problem that should guide theory selection.

Further clues may be provided by identifying applied economic research in parallel or similar problem domains, such as accounting, production, marketing and finance, which may provide tools useful in IT research. For example, work in pricing shared resources, such as telephone networks, in perishable inventories, such as baseball tickets, and in so-called free goods, such as parks and recreation facilities, provides useful analogues to the pricing of computer timesharing systems and communication networks [141]. Many economic aspects of IT resources, such as high fixed and low marginal costs or rapid obsolescence, bear striking similarities to other investment decisions. Work in rational expectations macroeconomics could provide the tools to study the role of information technology in transmitting information throughout the economy, thus propagating the adjustments effected by economic agents. Financial analysis techniques could help study the benefits when firms merge their IS operations, (e.g., this was reported to be the major source of operating efficiencies in several of the recent large mergers, such as Manufacturers Hanover Trust and Chemical).

Returning to the measurement issue, greater data sharing among researchers and greater use of secondary data in the economics of IT research is likely to reap substantial benefits [71]. It will also help to alleviate the shortage of well-established research instruments, and, as demonstrated by research in the hardware economies of scale, can lead to substantial progress in a relatively short amount of time.

In general, researchers in the intersection of IT and economics are well-positioned to create and exploit in the next five years a number of breakthroughs that will greatly advance the state of the art in MIS research, and will prove valuable to information systems professionals, thus advancing the state-of-practice as well. 
DRAFT of August 1991. For the final version see Decision Support Systems, December 1992, pp 365-386.

\section{REFERENCES}

[1] N. Ahituv, Assessing the Value of Information: Problems and Approaches, Proceedings of the Tenth International Conference on Information Systems, Boston, MA, December 1989, 315-326.

[2] P. Alpar and M. Kim, "A Microeconomic Approach to the Measurement of Information Technology Value", Journal of Management Information Systems, 7, 2 (1990) $55-69$.

[3] Y. Amihud and H. Mendelson, The Effects of Computer Based Trading on Volatility and Liquidity, in H.C. Lucas and R.A. Schwartz ed., The Challenge of Information Technology for the Securities Markets, R.D. Irwin, New York, 1989.

[4] L. Argote, S.L. Beckman and D. Epple, "The Persistence and Transfer of Learning in Industrial Settings", Management Science, 36, 2 (1990) 140-154.

[5] K. Arrow, "Technical Information, Returns to Scale, and the Existence of Competitive Equilibrium", IMSSS, Stanford University Technical Report 465, May 1985.

[6] K.J. Arrow, "Vertical Integration and Communication", Bell Journal of Economics, 6, (1975) 173-183.

[7] L. Arvan, "Sunk capacity costs, long-run fixed costs, and entry deterrence under complete and incomplete information", Rand Journal of Economics, 14, 1 (1986) 105-121.

[8] M.N. Baily and R.J. Gordon, "The Productivity Slowdown, Measurement Issues and the Explosion of Computer Power", The Brookings Institution Brookings Papers on Economic Activity 1988.

[9] J.Y. Bakos, Toward a More Precise Concept of Information Technology, Proceedings of the 6th International Conference on Information Systems, Indianapolis, Indiana, December 1985, 17-24.

[10] J.Y. Bakos, Dependent Variables for the Study of Firm and Industry-Level Impacts of Information Technology, Proceedings of the Eighth International Conference on Information Systems, Pittsburgh, Pennsylvania, December 6-9 1987,

[11] J.Y. Bakos, Interorganizational Information Systems: Strategic Opportunities for Competition and Cooperation, MIT Sloan School of Management Ph.D. thesis, 1987.

[12] J.Y. Bakos and M.E. Treacy, "Information Technology and Corporate Strategy: A Research Perspective", MIS Quarterly, 10, 2 (1986)

[13] R. Banker and R. Kauffman, Strategic Contributions of Information Technology: An Empirical Study of ATM Networks, Proceedings of the Ninth International Conference on Information Systems, Minneapolis, Minnesota, 1988, 141-150. 
DRAFT of August 1991. For the final version see Decision Support Systems, December 1992, pp 365-386.

[14] R. Banker and R.J. Kauffman, "Reuse and Productivity in an Integrated Computer Aided Software Engineering (ICASE) Environment: An Empirical Study at the First Boston Corporation", MIS Quarterly, 15, 3 (1991) forthcoming.

[15] R. Banker, R.J. Kauffman and R. Kumar, Output Measuremtn Metrics in an ObjectOriented Computer Aided SOftware Engineering (CASE) Environment: Critique, Evaluation and Proposal, Hawaii International Conference on System Sciences, January 1991, forthcoming.

[16] R. Banker, R.J. Kauffman and D. Zweig, "Factors Affecting Code Reuse: Implications for a Model of Computer Aided Software Engineering Development Performance", New York University Stern School of Business Working Paper IS-91-1, December 1990.

[17] R. Banker and C. Kemerer, "Performance Evaluation Metrics for Information Systems Development: A Principal-Agent Model", MIT Sloan School of Management Working Paper June 1991.

[18] R.D. Banker and S. Datar M., "Sensitivity, Precision and Linear Aggregation of Signals for Performance Evaluation", Journal of Accounting Research, 27, 1 (1989) 21-39.

[19] R.D. Banker, S.M. Datar and C.F. Kemerer, "A Model to Evaluate Variables Impacting Productivity on Software Maintenance Projects", Management Science, 37, 1 (1991) 1-18.

[20] R.D. Banker, S.M. Datar, C.F. Kemerer and D. Zweig, "Software Complexity and Software Maintenance Costs", MIT Sloan School Working Paper \#3155-90, March 1991.

[21] R.D. Banker and R.J. Kauffman, "Quantifying the Business Value of Information Technology: An Illustration of the 'Business Value Linkage' Framework", Stern School of Business, New York University Working Paper March 1991.

[22] R.D. Banker and C.F. Kemerer, "Scale Economies in New Software Development", IEEE Transactions on Software Engineering, SE-15, 10 (1989) 416-429.

[23] A. Barua, K.C. H. and T. Mukhopadhyay, "Information Technologies and Business Value: An Analytic and Empirical Investigation", College of Business, University of Texas at Austin Working Paper May 1991.

[24] A. Barua, C. Kriebel and T. Mukhopadhyay, "An Economic Analysis of Strategic Information Technology Investments", MIS Quarterly, (1991) forthcoming.

[25] A. Barua, C.H. Kriebel and T. Mukhopadhyay, MIS and Information Economics: Augmenting Rich Descriptions with Analytical Rigor in Information Systems Design, Proceedings of the 10th International Conference on Information Systems, Boston, MA, December 1989, 327-340. 
DRAFT of August 1991. For the final version see Decision Support Systems, December 1992, pp 365-386.

[26] C.M. Beath, Managing the User Relationship in IS Development Projects: A Transaction Governance Approach, Proceedings of the 8th International Conference on Information Systems, Pittsburgh, PA, December 1987, 415-427.

[27] C.M. Beath and D. Straub, Managing Information Resources at the Department Level: An Agency Perspective, Proceedings of the 22nd Hawaii International Conference on Systems Sciences, Kailua-Kona, Hawaii, January 1989, 151-159.

[28] B.D. Bernheim, "Strategic deterrence of sequential entry into an industry", Rand Journal of Economics, 15, (1984) 1-11.

[29] S. Besen M. and G. Saloner, "Compatibility Standards and the Market for Telecommunications Services", Massachusetts Institute of Technology Sloan School of Management Management in the 1990's Working Paper 88-049, May 1988.

[30] D. Blackwell, "Equivalent comparisons of experiments", Annals of Mathematical Statistics, 24, (1953) 265-272.

[31] B. Boehm, Software Engineering Economics, Prentice-Hall, Englewood Cliffs, NJ, 1981.

[32] B. Boehm, "Improving Software Productivity", Computer, 20, 9 (1987) 43-57.

[33] T.F. Bresnahan, "Measuring the Spillovers from Technical Advance: Mainframe Computers in Financial Services", American Economic Review, 76, 4 (1986) 742-755.

[34] E. Brynjolfsson, Information Technology and the Re-organization of Work: Theory and Evidence, MIT Sloan School of Management Ph.D. thesis, 1990.

[35] E. Brynjolfsson and B.A. Bimber, "Information Technology and the "Productivity Paradox": An Overview of Issues and Introduction to the Literature", MIT Laboratory for Computer Science Technical Report October 151989.

[36] E. Brynjolfsson, T.W. Malone and V. Gurbaxani, "Markets, Hierarchies and the Impact of Information Technology", MIT Sloan School of Management Working Paper 2113-88, December 1988.

[37] E. Brynjolfsson, T.W. Malone, V. Gurbaxani and A. Kambil, "Does Information Technology Lead to Smaller Firms?", MIT Center for Coordination Science Technical Report 106, November 1989.

[38] J.I. Bulow, "Durable Goods Monopolist", Journal of Political Economy, 90, (1982) 314-332.

[39] W. Chismar and J. Meier, The Economics of Switching Costs in Interorganizational Systems, 1989.

[40] W.G. Chismar and C.H. Kriebel, A Method for Assessing the Economic Impact of Information Systems Technology on Organizations, Proceedings of the Sixth International Conference on Information Systems, Indianapolis, Indiana, December 1985, 45-56. 
DRAFT of August 1991. For the final version see Decision Support Systems, December 1992, pp 365-386.

[41] C.U. Ciborra, Reframing the Role of Computers in Organizations: The Transaction Costs Approach, Proceedings of the Sixth International Conference on Information Systems, Indianapolis, Indiana, December 1985, 57-69.

[42] E.K. Clemons, "Evaluation of Strategic Investments in Information Technology", Communications of the ACM, 34, 1 (1991) 22-36.

[43] E.K. Clemons and J.T. Adams, International Opportunities for the Use of Information Systems in Securities Trading Created by Deregulation of the London Stock Exchange, Proceedings of the Ninth International Conference on Information Systems, Minneapolis, MN, December 1988, 129-139.

[44] E.K. Clemons and S. Kimbrough, Information Systems, Telecommunications, and their effects on Industrial Organization, Proceedings of the Seventh International Conference on Information Systems, San Diego, California, December 1986, 181-194.

[45] E.K. Clemons and M. Row, Structural Differences Among Firms: A Potential Source of Competitive Advantage in the Application of Information Technology, Proceedings of the Eighth International Conference on Information Systems, Pittsburgh, PA, December 1987, 19.

[46] E.K. Clemons and M. Row, Information Technology and Economic Reorganization, Proceedings of the 10th International Conference on Information Systems, Boston, MA, December 1989, 341-352.

[47] R.H. Coase, "The nature of the firm", Econ. N. S., 4, (1937) 386-405.

[48] K.J. Cohen and R.A. Schwartz, An Electronic Call Market: Its design and desirability, in H.C. Lucas and R.A. Schwartz ed., The Challenge of Information Technology for the Securities Markets, R.D. Irwin, New York, 1989.

[49] T.A. Corbi, "Program Understanding: Challenge for the 1990s", IBM Systems Journal, 28, 2 (1989) 294-306.

[50] D. Coursey, R.M. Isaac, M. Luke and V. Smith., "Market contestability in the presence of sunk (entry) costs", Rand Journal of Economics, 15, (1984) 69-84.

[51] W. Cron and M. Sobol, "The Relationship Between Computerization and Performance: A Strategy for Maximizing Economic Benefits of Computerization", Information and Management, 6, (1983) 171-181.

[52] K. Crowston and M. Treacy, Assessing the Impact of Information Technology on Enterprise Level Performance, Proceedings of the Seventh International Conference on Information Systems, San Diego, California, December 1986, 299-310.

[53] P. Davamanirajan, C.H. Kriebel and T. Mukhopadhyay, Information Technology Innovation and Competition in the Presence of Switching Costs, Proceedings of the 12th International Conference on Information Systems, New York, 1991, forthcoming. 
DRAFT of August 1991. For the final version see Decision Support Systems, December 1992, pp 365-386.

[54] P.A. David, Some New Standards for the Economics of Standardization in the Information Age, in P. Dasgupta and P. Stoneman ed., The Positive Sum Strategy: Harnessing Technology for Economic Growth, National Academy Press, Washington, DC, 1987.

[55] B.L. Dos Santos, "Justifying Investments in New Information Technologies", Journal of MIS, 7, 4 (1991) 71-90.

[56] P. Ein-Dor, "Grosch's law re-revisited: CPU power and the cost of computation", Communications of the ACM, 28, 2 (1985) 142-151.

[57] K. Eisenhardt, "Agency Theory: An Assessment and Review", Academy of Management Review, 14, 1 (1989) 57-74.

[58] J. Farrell, "Competition with Lock-in", University of California, Berkeley, Department of Economics Working Paper 8722, January 1987.

[59] J. Farrell and G. Saloner, "Installed Base and Compatibility: Innovation, Product Preannouncements, and Predation", American Economic Review, 76, 5 (1986) 940-955.

[60] J. Farrell and C. Shapiro, "Dynamic Competition with Lock-in", Princeton University, Woodrow Wilson School Discussion Paper 121, February 1987.

[61] D. Fundeberg and J. Tirole, "Capital as a commitment: strategic investment to deter mobility", Journal of Economic Theory,, 31, 2 (1983)

[62] J. Galbraith, Organization Design, Addison-Wesley, Reading, MA, 1973.

[63] J. Galbraith, Designing Complex Organizations, Addison-Wesley, Reading, MA, 1977.

[64] J.K. Galbraith, The New Industrial State, Houghton-Mifflin, Boston, MA, 1985.

[65] K.D. Garbade and W.L. Silber, "Technology, Communication and the Performance of Financial Markets: 1840-1975", Journal of Finance, 33, (1978) 819-832.

[66] D.K. Gode, A. Barua and T. Mukhopadhyay, On the Economics of the Software Replacement Problem, Proceedings of the 11th International Conference on Information Systems, Copenhagen, Denmark, December 1990, 159-170.

[67] S. Greenstein, "Creating Economic Advantage by Setting Compatibility Standards: Can 'Physical Tie-Ins' Extend Monopoly Power?", Stanford University Department of Economics Working Paper March 1988.

[68] V. Gurbaxani and C.F. Kemerer, An Agent-theoretic Perspective on the Management of Information Systems, Proceedings of the 22nd Hawaii International Conference on System Sciences, Kailua-Kona, Hawaii, January 1989, 141-150. 
DRAFT of August 1991. For the final version see Decision Support Systems, December 1992, pp 365-386.

[69] V. Gurbaxani and C.F. Kemerer, An Agency Theory View of The Management of End User Computing, Proceedings of the 11th International Conference on Information Systems, Copenhagen, Denmark, December 1990, 279-290.

[70] V. Gurbaxani and H. Mendelson, "Software and Hardware in Data Processing Budgets", IEEE Transactions on Software Engineering, SE-13, 9 (1987) 1010-1017.

[71] V. Gurbaxani and H. Mendelson, The Use of Secondary Analysis in MIS Research, Proceedings of the Harvard/UCI Workshop on Survey Research in MIS, Boston, MA, 1989,

[72] V. Gurbaxani and H. Mendelson, "An Integrative Model of Information Systems Spending Growth", Information Systems Research, 1, 1 (1990) 23-46.

[73] V. Gurbaxani and S. Whang, "The Impact of Information Systems on Organizations and Markets", Communications of the ACM, 34, 1 (1991) 59-73.

[74] S.E. Harris and J.L. Katz, Profitability and Information Technology Capital Intensity in the Insurance Industry, Proceedings of the HICSS Twenty First International Conference on System Sciences, Kailua-Kona, Hawaii, 1988, 124-130.

[75] S.E. Harris and J.L. Katz, Predicting Organizational Performance Using Information Technology Managerial Control Ratios, Proceedings of the HICSS Twenty Second International Conference on System Sciences, Kailua-Kona, Hawaii, 1989, 197-204.

[76] R.S. Hartman and D.J. Teece, "Product Emulation Strategies in the Presence of Reputation Effects and Network Externalities: Some Evidence from the Minicomputer Industry", University of California, Berkeley Economic Analysis and Policy Working Paper EAP-27, February 1988.

[77] M. Jensen, "Organization Theory and Methodology", Accounting Review, LVIII, 2 (1983)

[78] M. Jensen and W. Meckling, "Theory of the Firm: Managerial Behaviour, Agency Costs, and Ownership Structure", Journal of Financial Economics, 3, (1976) 305-360.

[79] Y.M. Kang, "Computer Hardware Performance: Production and Cost Function Analyses", Communications of the ACM, 32, 5 (1989) 586-593.

[80] Y.M. Kang, R.B. Miller and R.A. Pick, "Comments on "Grosch's law re-revisited: CPU power and the cost of computation", Communications of the ACM, 29, 8 (1986) 779781.

[81] M.L. Katz and C. Shapiro, "Network Externalities, Competition and Compatibility", American Economic Review, 75, (1985) 70-83.

[82] R.J. Kauffman, Assessing the Performance of Information Technologies Which Deliver Financial Services, Carnegie Mellon University Graduate School of Industrial Administration Ph.D. thesis, 1988. 
DRAFT of August 1991. For the final version see Decision Support Systems, December 1992, pp 365-386.

[83] R.J. Kauffman and P. Weill, An Evaluative Framework for Research on the Performance Effects of Information Technology Investment, Proceedings of the Tenth International Conference on Information Systems, Boston, MA, December 1989, 377-388.

[84] C.F. Kemerer, Measurement of Software Development Productivity, Carnegie Mellon University Ph.D. thesis, 1987.

[85] C.F. Kemerer, Software Production Economics: Theoretical Models and Practical Tools, Proceedings of the ACM 27th Annual Technical Symposium, Gaithersburg, Maryland, June 9 1988, 27-36.

[86] W.C. Kester, "Today's options for tomorrow's growth", Harvard Business Review, 62, 2 (1984) 153-160.

[87] P.D. Klemperer, Markets with Consumer Switching Costs, Stanford University Ph. D. thesis, 1986.

[88] P.D. Klemperer, "The Competitiveness of Markets with Switching Costs", Rand Journal of Economics, Vol.18, 1 (1987) 138-150.

[89] P.D. Klemperer, "Entry Deterrence in Markets with Consumer Switching Costs", Economic Journal Supplement, , 97, (1987)

[90] P.D. Klemperer, "Markets with Consumer Switching Costs", Quarterly Journal of Economics, (1987) 375-394.

[91] R. Klepper, An Agency Theory Perspective On Information Centers, Proceedings of the Twenty-Third Annual Hawaii International Conference on System Sciences, Kailua-Kona, Hawaii, January 1990, 251-259.

[92] R. Kling, K.L. Kraemer, J.L. King, J.Y. Bakos and V. Gurbaxani, Proposal on Coordination Theory and the Social Organization of Large-Scale Real-Time, Interactive Information Systems, Proposal submitted to NSF's Second Initiative on Coordination Science and Technology,1990.

[93] C.H. Kriebel, Understanding the Strategic Investment in Information Technology, in K.C. Laudon and J.A. Turner ed., Information Technology and Management Strategy, Prentice-Hall, Englewood Cliffs, NJ, 1989.

[94] C.H. Kriebel and R. Kaufmann, Modeling and Measuring the Business Value of Information Technology, in P. Berger, J.G. Kobielus and D.E. Sutherland ed., Measuring Business Value of Information Technologies, ICIT Press, Washington DC, 1988.

[95] C.H. Kriebel and J. Moore, Economics and Management Information Systems, Proceedings of the International Conference on Information Systems, Philadelphia, PA, December 1980, 19-31.

[96] B. Lientz and E.B. Swanson, Software Maintenance Management, Addison-Wesley, 1980. 
DRAFT of August 1991. For the final version see Decision Support Systems, December 1992, pp 365-386.

[97] G.W. Loveman, "The Productivity of Information Technology Capital", Massachusetts Institute of Technology Management in the 1990s Working Paper January 31, 1986.

[98] T.W. Malone, "Modeling Coordination in Organizations and Markets", Management Science, 33, 10 (1987) 1317-1332.

[99] T.W. Malone, "What is coordination theory?", MIT Sloan School of Management Working Paper 2051-88, 1988.

[100] T.W. Malone, R.I. Benjamin and J. Yates, "Electronic Markets and Electronic Hierarchies: Effects of Information Technology on Market Structure and Corporate Strategies", Communications of the ACM, 30, 6 (1987)

[101] T.W. Malone and K. Crowston, What is Coordination Theory and How Can It Help Design Cooperative Work Systems, Proceedings of the Conference on Computer Supported Cooperative Work, Los Angeles, CA, October 1990,

[102] T.W. Malone and S.A. Smith, "Modeling the performance of organizational structures", Operations Research, 36, 3 (1988) 421-436.

[103] J. Marschak, "The Payoff Relevant Description of States and Acts", Econometrica, 31, 4 (1963) 719-725.

[104] J. Marschak and R. Radner, Economic Theory of Teams, Yale University Press, New Haven, CT, 1972.

[105] C.B. McGuire and R. Radner, Decision and Organization, University of Minnesota Press, Minneapolis, MN, 1986.

[106] H. Mendelson, "Pricing Computer Services: Queueing Effects", Communications of the ACM, 28, 3 (1985) 312-321.

[107] H. Mendelson, "Economies of Scale in Computing: Grosch's Law Revisited", Communications of the ACM, 30, 12 (1987) 1066-1072.

[108] H. Mendelson and S. Whang, "Optimal Incentive-Compatible Priority Pricing for the M/M/1 Queue", Operations Research, (1990)

[109] G.R. Mitchell and W.F. Hamilton, "Managing R\&D as a Strategic Option", Research Technology Management, (1988) 15-22.

[110] J. Moore and A. Whinston, "A Model of Decision Making with Sequential Information Acquisition (Part 1)", Decision Support Systems, 2, (1986) 285-307.

[111] J. Moore and A. Whinston, "A Model of Decision Making with Sequential Information Acquisition (Part 2)", Decision Support Systems, 3, (1987) 47-72.

[112] National Science Foundation, Special Initiative on Coordination Theory and Technology, Directorate for Computer \& Information Science \& Engineering, Division of 
DRAFT of August 1991. For the final version see Decision Support Systems, December 1992, pp 365-386.

Information, Robotics \& Intelligent Systems, Information Technology \& Organizations Program,1988.

[113] National Science Foundation, Second Special Initiative on Coordination Theory and Technology, 1990.

[114] B.R. Nault, Interorganizational Information Technology Offered to Consumers: Pricing and Introduction, 1989.

[115] L.M. Nirenberg, "Advocating Investments in Information Technology", Competition Technology Corporation, 1350 Dell Avenue, Suite 201, Campbell CA 95008 Electric Power Research Institute Draft Report 8000-75, April 301990.

[116] P. Osterman, "The Impact of Computers on the Employment of Clerks and Managers", Industrial and Labor Relations Review, 39, (1986) 175-186.

[117] M.J. Parker and R.J. Benson, Information Economics: Linking Business Performance to Information Technology, Prentice Hall, Englewood Cliffs, New Jersey, 1988.

[118] J.W. Peake, M. Mendelson and R.T. Williams, Black Monday: Market Structure and Market-Making, in H.C. Lucas and R.A. Schwartz ed., The Challenge of Information Technology for the Securities Markets, R.D. Irwin, New York, 1989.

[119] E.T. Penrose, Theory of the Growth of the Firm, Blackwell, Oxford, 1959.

[120] M.E. Porter, Competitive Strategy, The Free Press, New York, NY, 1980.

[121] M.E. Porter and V.E. Millar, "How Information Gives You Competitive Advantage", Harvard Business Review, 63, 4 (1985) 149-160.

[122] R. Radner and J.E. Stiglitz, A Non-concavity in the Value of Information, in M. Boyer and R.E. Khilstrom ed., Bayesian Models in Economic Theory, Elsevier Science Publishers, 1984.

[123] J.F. Reinganum, "On the diffusion of new technology: A game theoretic approach", Review of Economic Studies, 48, (1981) 395-405.

[124] W.B. Richmond and A.B. Whinston, "Contract Theory and Information Systems Research", University of Rochester William E. Simon Graduate School of Business Administration Working Paper MERC-90-08, August 1990.

[125] S.S. Roach, "Technology and the Service Sector: America's Hidden Competitive Challenge", Morgan Stanley, New York Economic Perspectives August 1987.

[126] J.F. Rockart and M.S. Scott Morton, "Implications of Changes in Information Technology for Corporate Strategy", Interfaces, 14, 1 (1984) 84-95.

[127] G. Saloner, "Economic Issues in Computer Interface Standardization", Massachusetts Institute of Technology Sloan School of Management Working Paper February 1989. 
DRAFT of August 1991. For the final version see Decision Support Systems, December 1992, pp 365-386.

[128] S.C. Salop, Deregulating Self-Regulated Shared ATM Networks, Stanford University Center for Economic Policy Research Conference on Compatibility Standards and Information Technology: Business Strategy and Public Policy Issues, Palo Alto, California, February 1989,

[129] R. Schmalensee, Inter-Industry Studies of Structure and Performance (ch. 16), in R. Schmalensee and R.D. Willig ed., Handbook of Industrial Organization, North-Holland, New York, NY, 1989.

[130] R. Schmalensee and R.D. Willig, Handbook of Industrial Organization, NorthHolland, New York, NY, 1989.

[131] N.F. Schneidewind, "The State of Software Maintenance", IEEE Transactions on Software Engineering, SE-13, 3 (1987) 303-310.

[132] A.M. Spence, "The economics of internal organization: An introduction", Bell Journal of Economics, 6, (1975) 163-172.

[133] A.M. Spence, "Investment Strategy and Growth in a New Market", Bell Journal of Economics, 10, (1979) 1-19.

[134] A.M. Spence, "The Learning Curve and Competition", Bell Journal of Economics, 12, (1981) 49-70.

[135] C.B. Stabell and F. Forsund, "Productivity Effects of Computers in Administration: An Exploratory Empirical Investigation", Norwegian School of Economics and Business Administration Working Paper 1983.

[136] P.A. Strassman, Management Productivity as an IT Measure, in P. Berger, J.G. Kobielus and D.E. Sutherland ed., Measuring Business Value of Information Technologies, ICIT Press, Washington DC, 1988.

[137] N. Venkatraman and A. Zaheer, "Electronic Integration and Strategic Advantage: A Quasi-Experimental Study in the Insurance Industry", Information Systems Research, 1, 4 (1990) 377-393.

[138] C.C. von Weizsaker, "The Costs of Substitution", Econometrica, 52, (1984) 10851116.

[139] M. Weiss and M. Sirbu, Technological Choice in Voluntary Standards Committees: An Empirical Analysis, Stanford University Center for Economic Policy Research Conference on Compatibility Standards and Information Technology: Business Strategy and Public Policy Issues, February 24, 1989,

[140] S. Whang, "Cost Allocation Revisited: An Optimality Result", Management Science, $35,10(1989)$

[141] S. Whang, "Alternative Mechanisms of Allocating Computer Resources under Queuing Delays", Information Systems Research, 1, 1 (1990) 71-88. 
DRAFT of August 1991. For the final version see Decision Support Systems, December 1992, pp 365-386.

[142] S. Whang, "Inter-Firm Information Sharing", Graduate School of Business, Stanford University Working Paper 1990.

[143] S. Whang, "Software Contracts", Graduate School of Business, Stanford University working paper 1990.

[144] O. Williamson, Markets and Hierarchies, Free Press, New York, N.Y., 1975.

[145] R. Wilson, "Informational Economies of Scale", Bell Journal of Economics, 6, (1975) 184-195.

[146] C.D. Wrigley and A.S. Dexter, A Model for Estimating Information System Requirements Size: Preliminary Findings, Proceedings of the Ninth International Conference on Information Systems, Minneapolis, MN, December 1988, 129-139. 